\title{
Association between Oral Anticoagulation Knowledge, Anticoagulation Control, and Demographic Characteristics of Patients Attending an Anticoagulation Clinic in Saudi Arabia: A Cross-Sectional Prospective Evaluation
}

\author{
Ahmed Y Mayet \\ College of Pharmacy, King Saud University, P.O. Box 2457, Riyadh 11451, Saudi Arabia \\ *For correspondence: Email: iymayet@ksu.edu.sa, iymayet@gmail.com; Tel: 966507467280; Fax: +96614671985 \\ Revised accepted: 16 June 2015
}

\begin{abstract}
Purpose: To assess the level of knowledge on warfarin therapy and anticoagulation control, and explore the association between knowledge and anticoagulation control in a section of Saudi population. Methods: A cross-sectional prospective survey was conducted over a 4-week period in 2013 at King Khalid University Hospital outpatient anticoagulant clinic in Riyadh, Saudi Arabia. Adult patients who were either discharged on warfarin or taking warfarin and attending the outpatient anticoagulant clinic for $\geq 6$ months were invited to participate in the study. A questionnaire was used to collect the demographic data and knowledge of warfarin therapy (8-item). International Normalized Ratio (INR) readings were obtained from electronic-laboratory database. Good knowledge of warfarin was defined as a score of $\geq 75 \%$ and good (INR) control was defined as $\geq 75 \%$ Time INR in therapeutic range (TTR) calculated using Rosendaal method.

Results: A total of 105 patients completed the questionnaire with a response rate of $49.2 \%$. Seventynine patients (75.2\%) had good knowledge of warfarin (scored $\geq 75 \%$ ), but only 35 patients (33.3\%) had good anticoagulation control (TTR $\geq 75 \%)$. An association was observed between patients with no formal education and poor warfarin knowledge $(p=0.012)$. Smoking history was also linked with warfarin knowledge ( $p=0.025)$. INR control results significantly differed by marital status with divorced/widow status displaying poor INR control ( $p=0.028)$. Lastly, no association was found between good knowledge and good INR control (OR 1.35, $95 \%$; Cl $0.537-3.392$ ).

Conclusions: The majority of patients seen at the outpatient anticoagulation clinic have good knowledge of warfarin therapy although only a third showed good anticoagulation control. The results indicate no significant association between knowledge of warfarin therapy and anticoagulation control. Studies with a larger sample size are recommended to verify the foregoing results.
\end{abstract}

Keywords: Oral anticoagulant, Warfarin, International normalized ratio, Knowledge, Anticoagulation control

Tropical Journal of Pharmaceutical Research is indexed by Science Citation Index (SciSearch), Scopus, International Pharmaceutical Abstract, Chemical Abstracts, Embase, Index Copernicus, EBSCO, African Index Medicus, JournalSeek, Journal Citation Reports/Science Edition, Directory of Open Access Journals (DOAJ), African Journal Online, Bioline International, Open-J-Gate and Pharmacy Abstracts

\section{INTRODUCTION}

Warfarin is the most widely used anticoagulation drug worldwide including Saudi Arabia due to its ease of administration and low cost. The drug has a very low narrow therapeutic index and it provides effective anticoagulation for the treatment of thromboembolic conditions. In the US, 31 million prescriptions were written in 2004 for the treatment of these various 
thromboembolic conditions [1]. Warfarin has a fair safety and a tolerability profile providing that INR levels are kept within therapeutic range. The target INR ranges are between 2.0 to 3.0 for most indications except for mitral valve replacement (2.5 to 3.5$)$.

The improper use of warfarin is associated with unintentional bleeding and thrombosis as well as the lack of patients' knowledge, concurrent disease states, diet, and poor adherence to warfarin therapy [2-4]. Warfarin-associated intracerebral hemorrhage [5], with a $50 \%$ mortality rate, is one of the most severe adverse drug events (ADEs). A 2007 Mayo Clinic study estimated that the number of warfarin-related ICH ADEs was 8,000 to 10,000 each year [6]. From January 1993 to June 2006, $10 \%$ of warfarin-associated bleeding events reported to FDA's Adverse Events Reporting System were fatal [1]. Unintended thromboembolic events have also been reported as a result of inadequate anticoagulation. In 2013, Chen et al reported that high-risk patients, who were not compliant with warfarin therapy, had risks which were three times greater of VTE recurrence [7].

An association between patient knowledge of warfarin therapy, their demographic background, and therapeutic outcomes were also studied [2, 8-10]. The survey by Huet et al found that high family income, a high level of education and selfemployed status were linked with high warfarin knowledge scores [8]. Barcellona et al studied the association between knowledge of warfarin and anticoagulation control in 219 patients using a 6-item knowledge questionnaire. The study suggested a positive relationship between good INR control and high warfarin knowledge scores [9]. A study from Qatar also showed a positive association between knowledge of warfarin and good INR control on patients who were taking the drug for various thromboembolic conditions [10]. However, not all studies concur with such findings. Davis et al used an 18-question multiple-choice test to assess the association between patient demographic characteristics, knowledge of warfarin and anticoagulation control and results showed no positive associations [11].

The aim of this study is to assess the level of knowledge on warfarin therapy and anticoagulation control based on demographics and other characteristics and to explore association between knowledge and anticoagulation control in the Saudi population who have been prescribed warfarin.

\section{EXPERIMENTAL}

\section{Patients and methods}

A cross-sectional prospective survey was conducted over a 4-week period in October to November 2013 at King Khalid University Hospital outpatient anticoagulant clinic. The hospital is a tertiary care hospital in Riyadh, Saudi Arabia with a 1000 inpatient bed capacity. It provides medical services to Saudi citizens from all over the Kingdom. The anticoagulant clinic offers follow-up services to all hospitaldischarged patients who are prescribed anticoagulants. All adult patients ( $\geq 16$ years old) who were discharged from the hospital and who were expected to take warfarin and attend the outpatient anticoagulant clinic for $\geq 6$ months were invited to participate in the study. Patients were excluded from the study if they had disruption in warfarin therapy for $\geq 5$ days during the study period, were hospitalized during the study period for any reason, if they had an incomplete questionnaire or did not have four consecutive INR readings.

Prior to conducting the study, approval from the Institutional Review Board (IRB) was obtained. The study objective was explained prior to interview, and written consent was obtained if the patient verbally agreed to participate. The questionnaire was administered face-to-face by trained researchers; they were monitored to ensure quality of research.

The questionnaire comprised of three parts. The first part collected the patient demographic data including age, gender, educational level, occupation, and marital status. The second part of the questionnaire measured the knowledge using an 8-item survey questionnaire that was developed based on education and counseling of warfarin therapy provided to patients during their hospital discharge. The questions included fooddrug interactions; drug-drug interactions; the reasons for taking warfarin; actions to take in case of a missed dose or bleeding occurring while on warfarin; and the importance of notifying the use of warfarin to other health care providers during a visit to the anticoagulation clinic (Appendix 1). The questionnaire also contained a few questions from previously validated survey by Briggs et al with some modifications. They were translated to Arabic according to international guidelines [12,13]. The questionnaire was administered in Arabic language using a multiple choice question format. Each correct answer was given one point. Good knowledge was defined as a 
knowledge questionnaire score of $\geq 75 \%$ (6 out of 8 correct answers).

Lastly, the third part assessed the level of INR control. To assess the anticoagulation control, the most recent consecutive four INR readings, on an average of 4 weeks apart were obtained from the hospital central laboratory electronic data system for each patient. Anticoagulation control was defined as an INR that was between $2 \geq 3.0$ for all indications except for mitral valve replacement, where anticoagulation control was defined as an INR within the range of $2.5 \geq 3.5$. Good INR control was defined as percent Time INR in Therapeutic Range (TTR) $\geq 75 \%$ during study period using the Rosendaal method [14].

The questionnaire was validated in a crossover pilot study conducted on 20 patients who were at the time using warfarin. In a private designated counseling area, the researchers administered the questionnaire to patients on two separate occasions that were 2 weeks apart to avoid duplication of responses. For internal consistency of the knowledge on all questions of the pilot study, Cronbach's alpha was calculated. The value was 0.71 with good reliability.

The anticoagulation clinic used the hospital guideline adopted from the American College of Chest Physicians Evidence-Based Clinical Practice Guidelines (8th Edition) to adjust warfarin doses [15].

\section{Statistical analysis}

Descriptive statistics with counts and percentages were used to illustrate the results. Alongside this, Chi-square tests and Fisher's exact test were used to detect if there were any associations between demographic characteristics, knowledge and anticoagulation control. A logistics analysis was used to detect any association among demographic background, knowledge and anticoagulation control. A $p$-value of $<0.05$ was considered as statically significant. Statistical analyses were conducted using the Statistical Package for Social Science (SPSS) software, version 18.0 (SPSS Inc., Chicago, IL).

\section{RESULTS}

\section{Patients}

A total of 232 patients attended the outpatient anticoagulation clinic during study period and out of this figure, 118 patients accepted to partake in the study which is a response rate of $49.2 \%$. It must be noted that 13 patients were excluded from the analysis due to the following reasons: incomplete INR results (3 patients), disruption in warfarin therapy ( 2 patients), and a substantial number of survey questions were not answered (8 patients). The demographic and other patient characteristics of the 105 patients are summarized in relation to their knowledge and level of anticoagulation control in Tables 1 and 2.

The mean age of the study population was 55.4 SD \pm 15.3 years. Of the 105 participants, 69 $(65.7 \%)$ were female, $71(67.6 \%)$ were aged 50 and above, 84 (81.6\%) were non-smokers and 76 (74.5\%) were married. Also, 40 (38.8 \%) participants had not had any formal education and a low figure of 17 (16.5\%) had a university diploma. Twenty-nine participants (27.6 \%) stated to have a job and the remainder were unemployed. The majority $(61,61.6 \%)$ said they always attended the anticoagulation clinic without missing appointments and the remainder stated they could not always attend the clinic. The most common indications for warfarin therapy were deep vein thrombosis and pulmonary embolism $(47,48.0 \%)$ followed by prosthetic heart valve $(22,22.4 \%)$ and atrial fibrillation (11, 11.2 \%).

\section{Anticoagulation control}

The mean \pm SD INR values obtained for four readings were as follows: INR 1st reading 2.45 , $\mathrm{SD} \pm 0.88$, range 0.97 to 8.02 ; INR 2 nd reading 2.57 , SD \pm 0.82 , range 1.05 to 5.77 ; INR 3rd reading $2.70, S D \pm 0.90$, range 0.93 to 6.71 , and 4 th reading $2.79, S D \pm 0.84$, range 1.16 to 6.71. The mean INR follow-up days were 115 SD \pm 44 . Only 35 (33.3 \%) participants had good anticoagulation control (TTR $\geq 75 \%$ ) during the study period. Of the 70 participants with poor anticoagulation control (TTR < $75 \%$ ), 29 (41.4 $\%$ patients had INR values below the therapeutic range and $41(58.6 \%)$ had INR values above the therapeutic range. Fisher's exact test showed good INR control significantly differed by marital status with the divorced/widow status associated with poor INR control ( $p=$ 0.028).

\section{Knowledge of warfarin therapy}

Seventy-nine $(75.2 \%)$ patients demonstrated good knowledge of warfarin (scored $\geq 75 \%$ ). Overall, 54 (51.4\%) patients scored $100 \%$ on knowledge questions whereas only 12 (11.4\%) scored $<50 \%$. 
Table 1: Association between demographics plus other patient characteristics and anticoagulation control

\begin{tabular}{|c|c|c|c|c|}
\hline \multirow[t]{2}{*}{ Characteristics } & \multirow[t]{2}{*}{ Total } & \multicolumn{3}{|c|}{ Percent time INR values within therapeutic range (TTR) } \\
\hline & & $\begin{array}{c}<75 \% \\
\text { Poor control }\end{array}$ & $\begin{array}{c}\geq 75 \% \\
\text { Good control }\end{array}$ & $P$-value \\
\hline \multicolumn{5}{|l|}{ Gender ( $n=105)$} \\
\hline Male & $36(34.3)$ & $21(58.3)$ & $15(41.7)$ & \multirow[b]{2}{*}{$0.191^{* *}$} \\
\hline Female & $69(65.7)$ & $49(71.0)$ & $20(29.0)$ & \\
\hline \multicolumn{5}{|l|}{ Marital status ( $n=102)$} \\
\hline Married & $76(74.5)$ & $50(65.8)$ & $26(34.2)$ & \multirow{3}{*}{$0.028^{*}$} \\
\hline Unmarried & $11(10.8)$ & $5(45.5)$ & $6(54.5)$ & \\
\hline Divorced/ widow & $15(14.7)$ & $14(93.3)$ & $1(6.7)$ & \\
\hline \multicolumn{5}{|l|}{ Age group (n=105) } \\
\hline$<50$ & $34(32.4)$ & $23(67.5)$ & $11(32.5)$ & \multirow{3}{*}{$0.998^{* *}$} \\
\hline 50 to 70 & $53(50.5)$ & $35(66.0)$ & $18(34.0)$ & \\
\hline$>70$ & $18(17.1)$ & $12(66.7)$ & $6(33.3)$ & \\
\hline \multicolumn{5}{|l|}{ Educational level ( $n=103)$} \\
\hline No formal education & $40(38.8)$ & $29(72.5)$ & $11(27.5)$ & \multirow{3}{*}{$0.569^{* *}$} \\
\hline High/Middle school & $46(44.7)$ & $30(65.2)$ & $16(34.7)$ & \\
\hline Diploma/ University & $17(16.5)$ & $10(58.8)$ & $7(41.2)$ & \\
\hline \multicolumn{5}{|l|}{ Occupation $(n=98)$} \\
\hline Employed & $29(29.6)$ & $18(62.1)$ & $11(37.9)$ & \multirow[b]{2}{*}{$0.731^{* *}$} \\
\hline Unemployed & $69(70.4)$ & $47(68.1)$ & $22(31.9)$ & \\
\hline \multicolumn{5}{|l|}{ Smoking history ( $n=103)$} \\
\hline Non smoker & $84(81.6)$ & $55(65.5)$ & $29(34.5)$ & \multirow[b]{2}{*}{$0.923^{* *}$} \\
\hline Smoker & $18(17.4)$ & $12(66.7)$ & $6(33.3)$ & \\
\hline \multicolumn{5}{|c|}{ Reason for taking warfarin $(n=98$} \\
\hline Atrial fibrillation & $11(11.2)$ & $8(72.7)$ & $3(27.3)$ & \multirow{4}{*}{$0.672^{*}$} \\
\hline DVT/PE & $47(48.0)$ & $31(66.0)$ & $16(34.0)$ & \\
\hline Prosthetic heart valve & $22(22.4)$ & $16(72.7)$ & $6(27.3)$ & \\
\hline Others & $18(18.4)$ & $12(66.7)$ & $6(33.3)$ & \\
\hline \multicolumn{5}{|l|}{ Clinic attendance $(n=99)$} \\
\hline Always attend clinic & $61(61.6)$ & $44(71.1)$ & $17(27.8)$ & \multirow[b]{2}{*}{$0.214^{* *}$} \\
\hline Not always attend clinic & $38(38.4)$ & $22(57.9)$ & $16(42.1)$ & \\
\hline
\end{tabular}

DVT/PE: deep vein thrombosis/pulmonary embolism. *Fisher's exact test. ${ }^{* *}$ Chi square test

The level of knowledge on warfarin therapy was only associated with education level and smoking status. No formal education contributed to poor warfarin knowledge compared to other groups ( $p$ $=0.012$ ). Warfarin knowledge significantly differed by smoking status with non-smoking status being associated with poor knowledge ( $p$ $=0.028)$. No other link was found between warfarin knowledge and any other demographic characteristics (Table 2).

\section{Association between knowledge and anticoagulation control}

Seventy-nine $(75.2 \%)$ patients had good knowledge of warfarin (scored $\geq 75 \%$ ), but only $35(33.3 \%)$ patients had good anticoagulation control (TTR $\geq 75 \%$ ). No association was found between good knowledge and good INR control
(OR: 1.35, $95 \%$ Cl $0.537-3.392, p=0.522$ Table 3).

\section{DISCUSSION}

This is the first study to investigate the knowledge of warfarin therapy and anticoagulation control (INR) based on patients' demographic characteristics. This study explored the association between knowledge and anticoagulation control within the Saudi population. A third of the patients $(33.3 \%)$ at King Khalid University Hospital had good INR control. The results of good INR control from previously published studies in the literature range from $14 \%$ to $48 \%$. The study by Davis et al showed that only $14 \%$ of patients who were prescribed warfarin achieved good anticoagulation control, defined as more than 70 $\%$ of INR values within therapeutic range [11]. 
Table 2: Association between demographic plus other characteristics and knowledge score

\begin{tabular}{|c|c|c|c|c|}
\hline \multirow[t]{2}{*}{ Characteristics } & \multirow[t]{2}{*}{ Total } & \multicolumn{3}{|c|}{ Knowledge Score } \\
\hline & & $\begin{array}{c}<75 \% \\
\text { Poor knowledge }\end{array}$ & $\begin{array}{c}\geq 75 \% \\
\text { Good knowledge }\end{array}$ & $P$-value \\
\hline \multicolumn{5}{|l|}{ Gender (105) } \\
\hline Male & $36(34.3)$ & $6(16.7)$ & $30(83.3)$ & $0.165^{*}$ \\
\hline Female & $69(65.7)$ & $2(26.3)$ & $49(66.7)$ & \\
\hline \multicolumn{5}{|l|}{ Marital status (102) } \\
\hline Married & $76(74.5)$ & $17(22.7)$ & $59(77.6)$ & $0.649^{*}$ \\
\hline Unmarried & $11(10.8)$ & $3(27.3)$ & $8(72.7)$ & \\
\hline Divorced/widow & $15(14.7)$ & $5(33.3)$ & $10(67.7)$ & \\
\hline \multicolumn{5}{|l|}{ Age group (105)) } \\
\hline$<50$ & $34(32.4)$ & $6(17.6)$ & $28(82.4)$ & $0.215^{\star}$ \\
\hline 50 to 70 & $53(50.5)$ & $17(32.1)$ & $36(67.9)$ & \\
\hline$>70$ & $18(17.1)$ & $3(16.7)$ & $15(83.3)$ & \\
\hline \multicolumn{5}{|l|}{ Educational level (103) } \\
\hline No formal education & $40(38.8)$ & $16(40.0)$ & $24(60.0)$ & $0.012^{*}$ \\
\hline High/Middle school & $46(44.7)$ & $7(15.2)$ & $39(84.8)$ & \\
\hline Diploma/ University & $17(16.5)$ & $2(11.8)$ & $15(88.2)$ & \\
\hline \multicolumn{5}{|l|}{ Occupation (98) } \\
\hline Employed & $29(29.6)$ & $4(13.8)$ & $25(86.2)$ & $0.292^{*}$ \\
\hline Unemployed & $69(70.4)$ & $16(23.2)$ & $53(76.8)$ & \\
\hline \multicolumn{5}{|l|}{ Smoking history (102) } \\
\hline Non-smoker & $84(81.6)$ & $25(29.8)$ & $59(70.2)$ & $0.025^{*}$ \\
\hline Smoker & $18(17.4)$ & $1(5.6)$ & $17(94.4)$ & \\
\hline \multicolumn{5}{|l|}{$\begin{array}{l}\text { Reason for taking warfarin } \\
\text { (98) }\end{array}$} \\
\hline Atrial fibrillation & $11(11.2)$ & $4(36.4)$ & $7(63.6)$ & $0.335^{*}$ \\
\hline DVT/PE & 47 (48.0) & $10(21.3)$ & $37(78.7)$ & \\
\hline Prosthetic heart valve & $22(22.4)$ & $3(13.6)$ & $19(86.4)$ & \\
\hline Other & $18(18.4)$ & $2(11.1)$ & 16 (88.9) & \\
\hline \multicolumn{5}{|l|}{ Clinic attendance } \\
\hline Always attend clinic & $61(61.6)$ & $11(18.0)$ & $50(82.0)$ & $0.228^{* *}$ \\
\hline Not always attend clinic & $38(38.4)$ & $11(28.9)$ & $27(71.1)$ & \\
\hline
\end{tabular}

Table 3: Association between anticoagulation control and knowledge score

\begin{tabular}{|c|c|c|c|}
\hline \multirow{2}{*}{$\begin{array}{l}\text { Anticoagulation control } \\
\text { (TTR) }\end{array}$} & \multicolumn{2}{|c|}{ Knowledge score } & \multirow[t]{2}{*}{$P$-value } \\
\hline & $\begin{array}{l}<75 \% \\
n=26\end{array}$ & $\begin{array}{c}\geq 75 \% \\
n=79\end{array}$ & \\
\hline $\begin{array}{l}\text { Percent time INR values within } \\
\text { therapeutic range }(T T R) \geq 75 \%(n=35)\end{array}$ & $10(28.6)$ & $25(71.4)$ & 0.522 \\
\hline $\begin{array}{l}\text { Percent time INR values within } \\
\text { therapeutic range (TTR) }<75 \%(n=70)\end{array}$ & $16(22.9)$ & $54(77.1)$ & \\
\hline
\end{tabular}

The study sample size was small with only 52 participants and TTR percent was calculated on the INR result obtained only within 60 days prior to survey completion. The study by Khudair et al from Qatar showed that despite patients receiving education on warfarin therapy, only 68 patients $(48 \%)$ achieved good anticoagulation control [10]. However, the most widely used Rosenadaal Method was not used to calculate TTR for INR control. Likewise, the study by Kagansky et al showed that even after providing education on warfarin therapy to 323 elderly, only $45.1 \%$ achieved good anticoagulation control [4]. Good anticoagulation control was defined as INR values between 2 and 3 and not based on TTR.
A number of factors can affect coagulation control whilst on warfarin therapy [16]. Genetic variation of disposing warfarin by the liver could potentially be a factor that contributes to poor anticoagulation in patients but this is unlikely within the Saudi population. The study conducted by Saour et al showed that the prevalence of the CYP2C9 polymorphism in the Saudi population is low $(36 \%)$ and is similar to that seen in Caucasians. Populations with high CYP2C9 polymorphism require $40 \%$ less warfarin and serious bleeds are more likely to occur with normal warfarin doses [17].

It can be suggested that poor adherence to warfarin therapy may have contributed to poor 
anticoagulation control in this study. Previous studies have shown that adherence to warfarin therapy is significantly associated with anticoagulation (INR) control $[3,10,11]$. It is recommended that future studies are required in order to examine such effect on the population.

In this study, 79 patients $(75 \%)$ had good knowledge of warfarin. Baker et al has previously surveyed anticoagulation knowledge of patients receiving warfarin therapy in an outpatient anticoagulation clinic similar to the setting in this study, and used a validated 29-item anticoagulation knowledge assessment questionnaire. The results showed that $74.1 \%$ of patients had good knowledge of warfarin (score $\geq 72.4$ $\%$ ), which is comparable to the findings in this study [18]. However, the study from Qatar showed that only 78 patients $(56 \%)$ had satisfactory knowledge (score $\geq 75 \%$ ) of warfarin. The study used a 12-item questionnaire similar to the current survey, although the demographic characteristics differed from the patients in this study [10]. There were more male participants $(64 \%)$ with various ethnic backgrounds [10].

This study did not find that good knowledge of warfarin therapy contributed to good INR control in patients. Regardless of the fact that $75.2 \%$ of patients had a good level of knowledge on warfarin therapy, only $33.3 \%$ showed good INR control. Conflicting results have been reported in literature regarding the relationship between warfarin knowledge and anticoagulation control. Davis et al and the Newcastle Anticoagulation Study Group reported a lack of association between anticoagulation control and knowledge of warfarin therapy in their patients $[11,19]$. On the contrary, other researchers have reported a positive association between good knowledge of warfarin and good anticoagulation control $[2,9,10,20]$.

\section{Limitations of the study}

This study has a number of limitations that must be reported. The surveyors were unable to control patients' comorbid conditions and some other variables such as behavioral, social and physiologic factors that can affect anticoagulation control. The anticoagulation clinic used designated guidelines to adjust the warfarin dose for consistency [15]. Although the guidelines are provided at the clinic, the knowledge and attitudes of physicians regarding the use of warfarin in various conditions are varied which might affect anticoagulation [21]. The surveyors used same two researchers during the entire study to administer the questionnaire face to face instead of using a self-administered questionnaire to minimize the response variation.

\section{CONCLUSION}

This study demonstrates that a majority of patients seen at the outpatient anticoagulation clinic have good knowledge of warfarin therapy although many showed poor anticoagulation control. No link was found between knowledge of warfarin therapy and anticoagulation control. Further studies are needed to examine whether there is an association between adequate adherence of warfarin therapy and anticoagulation control.

\section{ACKNOWLEDGEMENT}

This project was supported by King Saud University (KSU) - Liver Disease Research Center, Riyadh, Saudi Arabia. The author would like to acknowledge Rosemary Collier, PhD, for providing editing support.

\section{REFERENCES}

1. Wysowski DK, Nourjah $P$, Swartz L. Bleeding complications with warfarin use: a prevalent adverse effect resulting in regulatory action. Arch Intern Med. 2007; 167: 1414-419.

2. Tang EO, Lai CS, Lee KK, Wong RS, Cheng G, Chan TY. Relationship between patients' warfarin knowledge and anticoagulation control. Ann Pharmacother. 2003; 37: 34-39.

3. Kumar S, Haigh JR, Rhodes LE, Peaker S, Davies JA, Roberts BE, Feely MP. Poor compliance is a major factor in unstable outpatient control of anticoagulant therapy. Thromb Haemost. 1989; 62: 729-732.

4. Kagansky N, Knobler H, Rimon E, Ozer Z, Levy S. Safety of anticoagulation therapy in well-informed older patients. Arch Intern Med. 2004; 164: 2044-2050.

5. Guidance for Industry: Q2B Validation of Analytical Procedures: Methodology, ICH Harmonised Tripartite Guideline. Nov 1996.

6. Aguilar MI, Hart RG, Kase CS, Freeman WD, Hoeben BJ, Garcia RC, Ansell JE, Mayer SA, Norrving B, Rosand $\mathrm{J}$, et al. Treatment of warfarin-associated intracerebral hemorrhage: literature review and expert opinion. Mayo Clin Proc. 2007; 82: 82-92.

7. Chen SY, Wu N, Gulseth M, LaMori J, Bookhart BK, Boulanger L, Fields L, Schein J. One-year adherence to warfarin treatment for venous thromboembolism in high-risk patients and its association with long-term risk of recurrent events. J Manag Care Pharm. 2013; 19: 291-301.

8. Hu A, Chow CM, Dao D, Errett L, Keith M. Factors influencing patient knowledge of warfarin therapy 
after mechanical heart valve replacement. $J$ Cardiovasc Nurs. 2006; 21: 169-175; quiz 76-77.

9. Barcellona D, Contu P, Marongiu F. Patient education and oral anticoagulant therapy. Haematologica. 2002; 87: 1081-1086.

10. Khudair IF, Hanssens YI. Evaluation of patients' knowledge on warfarin in outpatient anticoagulation clinics in a teaching hospital in Qatar. Saudi Med J. 2010; 31: 672-677.

11. Davis NJ, Billett HH, Cohen HW, Arnsten JH. Impact of adherence, knowledge, and quality of life on anticoagulation control. Ann Pharmacother. 2005; 39: 632-636.

12. Wild $D$, Grove $A$, Martin $M$, Eremenco $S$, McElroy $S$, Verjee-Lorenz A, Erikson P, Translation ITFf, Cultural A. Principles of Good Practice for the Translation and Cultural Adaptation Process for Patient-Reported Outcomes (PRO) Measures: report of the ISPOR Task Force for Translation and Cultural Adaptation. Value Health. 2005; 8: 94-104.

13. World Health Organization. Process of translation and adaptation of instruments. [http://www.who.int/ substance_abuse/research_tools/translation/en/]. WHO. 2007.

14. Rosendaal FR, Cannegieter SC, van der Meer FJ, Briet $E$. A method to determine the optimal intensity of oral anticoagulant therapy. Thrombosis and haemostasis. 1993; 69: 236-239.
15. Hirsh J, Guyatt G, Albers GW, Harrington $R$, Schunemann HJ, American College of Chest $P$. Executive summary: American College of Chest Physicians Evidence-Based Clinical Practice Guidelines (8th edn). Chest. 2008; 133: 71S-109S.

16. Ansell J, Hirsh J, Dalen J, Bussey H, Anderson D, Poller $L$, Jacobson A, Deykin D, Matchar D. Managing oral anticoagulant therapy. Chest. 2001; 119: 22S-38S.

17. Saour JN, Shereen AW, Saour BJ, Mammo LA. CYP2C9 polymorphism studies in the Saudi population. Saudi Med J. 2011; 32: 347-352.

18. Baker JW, Pierce KL, Ryals CA. INR goal attainment and oral anticoagulation knowledge of patients enrolled in an anticoagulation clinic in a Veterans Affairs medical center. J Manag Care Pharm. 2011; 17: 133-142.

19. The Newcastle Anticoagulation Study Group. Effectiveness of anticoagulation among patients discharged from hospital on warfarin. Med J Aust. 1998; 169: 243-246.

20. Roddie AM, Pollock A. Therapeutic control of anticoagulation: how important is patient education? Clin Lab Haematol. 1988; 10: 109-112.

21. Monette J, Gurwitz JH, Rochon PA, Avorn J. Physician attitudes concerning warfarin for stroke prevention in atrial fibrillation: results of a survey of long-term care practitioners. J Am Geriatr Soc. 1997; 45: 1060-1065. 